\title{
PENGARUH PENAMBAHAN SIRTU TERHADAP NILAI CBR SUBGRADE RUAS JALAN KOYA TENGAH DISTRIK MUARA TAMI KOTA JAYAPURA (QUARRY SIRTU HARAPAN KABUPATEN JAYAPURA)
}

\author{
Alfian Adie Chandra \\ Teknik Sipil Universitas Cenderawasih \\ alfiansipiluncen@gmail.com
}

\begin{abstract}
ABSTRAK
Permasalahan daya dukung tanah dasar merupakan salah satu hal yang sangat perlu diperhatikan dalam suatu perencanaan dan pekerjaan suatu konstruksi bangunan sipil. Hal ini dikarenakan tanah berfungsi sebagai media yang menahan beban atau aksi dari konstruksi yang dibangun di atasnya. Perubahan cuaca dan suhu di lapangan merupakan faktor yang menjadikan tanah tidak stabil. Telah banyak stabilisasi yang telah dilakukan menggunakan soil semen namun membutuhkan biaya yang tidak sedikit dan juga hasil pelaksanaan stabilisasi tanah tersebut berumur relatif pendek. Oleh karena itu Penelitian ini dilakukan dengan menggunakan campuran sirtu dengan variasi campuran sebanyak 15\%, 20\% dan $30 \%$. Semakin banyak variasi campuran sirtu yang ditambahkan mengakibatkan kadar air semakin menurun yang akan membuat nilai daya dukung tanah meningkat, nilai batas plastis meningkat, sedangkan nilai batas cair dan indeks plastisitas pada tanah menurun.
\end{abstract}

Kata kunci : Stabilisasi, Sirtu, CBR

\begin{abstract}
The problem of subgrade bearing capacity is one thing that really needs to be considered in the planning and work of a civil building construction. This is because the soil functions as a medium that supports the load or action of the construction built on it. Changes in weather and temperature in the field are factors that make the soil unstable. There has been a lot of stabilization that has been carried out using soil cement but it requires a lot of money and also the results of the implementation of soil stabilization are relatively short-lived. Therefore, this study was conducted using a mixture of sirtu with mixed variations of $15 \%, 20 \%$ and $30 \%$. The more variations in the mixture of sirtu that are added, the water content decreases which will make the carrying capacity of the soil increase, the plastic limit value increases, while the liquid limit value and the plasticity index in the soil decrease.
\end{abstract}

Key words : Stabilization, Sirtu, CBR 


\section{PENDAHULUAN}

Tanah merupakan salah satu material yang langsung tersedia dilapangan, apabila suatu tanah yang akan digunakan tidak memenuhi kriteria yang di syaratkan untuk tujuan tertentu maka tanah tersebut harus diperbaiki sifatsifatnya, karena sifat-sifat tanah dilapangan tidak selalu memenuhi kriteria, maka tanah tersebut harus distabilisasi sehingga dapat memenuhi syarat-syarat teknis yang diperlukan. Stabilisasi tanah yang dilakukan pada tanah berguna untuk memperbiki sifat-sifat teknis tanah.Masalah pada tanah yang sering kita temui dilapangan adalah terjadinya perubahan kadar air yang mengakibatkan perubahan volume tanah sehingga saat musim hujan tanah cenderung mengembang akibat dari infiltrasi air hujan dan mengalami penyusutan saat musim kemarau akibat proses penguapan pada lapisan permukaan dan akibat penurunan muka air tanah.Sampel tanah yang digunakan pada pengujian ini merupakan jenis tanah yang diambil dari lokasi kelurahan Koya Tengah, Distrik Muara Tami, Kota Jayapura.Serta sirtu yang akan digunakan sebagai bahan tambah/stabilisasi pada tanah dasar, jenis sirtu yang digunakan sebagai bahan tambah/stabilisasi diambil dari Harapan, Kabupaten Jayapura. Penelitian ini penulis menguji bagaimana pengaruh penambahan sirtu 15\%, 20\%, dan 30\% terhadap nilai CBR di kelurahan Koya Tengah, Distrik Muara Tami, Kota Jayapura.

\section{TINJAUAN PUSTAKA}

Tanah lempung dan mineral lempung adalah tanah yang memiliki partikelpartikel mineral tertentu yang "menghasilkan sifat-sifat plastis pada tanah bila dicampur dengna air" (Grim, 1953). ASTMD-653 memberikan batasan bahwa secara fisik ukuran lempung adalah partikel yang berukuran antara 0,002 mm samapi 0,005 mm. Sifat-sifat yang dimiliki tanah lempung (Hardiyatmo, 1999) adalah sebagai berikut:

1. Ukuran butir halus, kurang dari $0,002 \mathrm{~mm}$

2. Permeabilitas rendah

3. Kenaikan air kapiler tinggi

4. Bersifat sangat kohesif

5. Kadar kembang susut yang tinggi

6. Proses konsolidasi lambat.

Sirtu adalah singkatan dari pasir batu, karena komposisi ukuran butir yang tidak seragam.

Subgrade atau tanah dasar merupakan fondasi yang menopang beban perkerasan yang berasal dari kendaraan yang melewati suatu jalan. Prosedur Pelaksanaan Pekerjaan Subgrade. Subgrade adalah tanah dasar di bagian bawah lapis perkerasan jalan. Langkah-langkah pelaksanaannya :

1. Apabila tanah exsisting lebih tinggi dari elevasi rencana, maka dilakukan pekerjaan galian.

2. Pemadatan sub grade menggunakan Vibrator Roller atau Static Roller (sambil diberi air secukupnya untuk mencapai kadar air optimum).

3. Setelah pemadatan tanah dasar selesai, lalu dilakukan perataan menggunakan Motor Grader.

Cara Pengukuran Kualitas Sub Grade 
Lapisan tanah dasar (sub grade) adalah lapisan tanah yang berfungsi sebagai tempat perletakan lapis perkerasan dan mendukung konstruksi perkerasan jalan diatasnya.

Metode perencanaan perkerasan jalan yang umum dipakai adalah cara-cara empiris dan yang biasa dikenal adalah cara CBR (California Bearing Ratio). Metode ini dikembangkan oleh California State Highway Departement sebagai cara untuk menilai kekuatan tanah dasar jalan (subgrade). Harga CBR adalah nilai yang menyatakan kualitas tanah dasar dibandingkan dengan bahan standar berupa batu pecah yang mempunyai nilai CBR sebesar $100 \%$ dalam memikul beban.

Menurut AASHTO T-193-74 dan ASTM D-1883-73, California Bearing Ratio adalah perbandingan antara beban penetrasi suatu beban terhadap beban standar dengan kedalaman dan kecepatan penetrasi yang sama. Menurut Soedarmo dan Purnomo (1997), berdasarkan cara mendapatkan contoh tanah, CBR dapat dibagi atas :

1. CBR lapangan (CBR inplace atau field CBR).

2. CBR lapangan rendaman (undisturbed soaked CBR).

3. CBR rencana titik (laboratory CBR).

Perancangan campuran dilakukan untuk merubah sifat-sifat tanah pada sirtu minimal yang dapat mempertahankan daya tahannya sampai ke tingkat tertentu yang diinginkan. Untuk hal ini, metode perancangan campuran ditunjukan pada (Rolling dan Rolling, 1996) :

1. Tujuan yang akan dicapai : reduksi indeks plastisitas (PI), perubahan tekstur tanah, reduksi pengembangan, kenaikkan kekuatan atau kenaikan kekuatan jangka panjang.

2. Keawetan atau daya tahan (Durability) : kemampuan untuk memelihara sifatsifatnya pada waktu yang dibutuhkan.

3. Ekonomis : Kadar sirtu minimum untuk tercapainya tujuan dan memelihara keaweta yang dibutuhkan

\section{METODOLOGI PENELITIAN}

Tahapan persiapan kegiatan dilakukan sebelum memulai pengumpulan data dan pengolahannya. Tahap persiapan ini meliputi kegiatan-kegiatan sebagai berikut :

1. Menentukan keperluan data primer dan data sekunder.

2. Studi pustaka tentang stabilisasi tanah lempung sebagai referensi dan tambahan.

Penelitian dilakukan di laboratorium Jurusan Teknik Sipil Universitas Cenderawasih yang bertujuan untuk mengetahui komposisi tanah lempung dan sirtu agar dapat memperoleh tingkat kekakuan.

Bahan yang digunakan

1. Tanah

Pengambilan sampel tanah lempung diambil dari Kelurahan Koya Timur, Distrik Muara Tami, Kota Jayapura. Pengambilan sampel tanah diambil dengan menggunakan cangkul dan dimasukan kedalam karung untuk diangkut. Contoh sampel tanah yang diambil, kemudia dijemur sampai kering, gumpalan gumpalan tanah dipecah dengan palu karet kemudia disaring dengan saringan no.4. Contoh yang digunakan adalah yang lolos saringan no.4, dimaksudkan agar pengujian dibebaskan dari gumpalan tanah yang lebih besar saringan no.4.

2. Sirtu alam 
Sirtu alam yang digunakan diambil dari quarry Harapan, Kabupaten Jayapura Alat, Pengujian ini dilakukan berdasarkan acuan sebagai berikut :

1. Alat uji kadar air (SNI 03-1965-1990)

2. Alat uji berat jenis (SNI 03-1965-1990)

3. Alat uji Atterberg Limits :

a. Uji batas cair (SNI 03-1967-1990)

b. Uji batas plastis (SNI 03-1966-1990)

c. Uji batas susut (SNI 03-3422-1994)

4. Alat analisis ukuran butiran (SNI 03-3423-1994)

5. Alat hydrometer (SNI 03-3422-1994)

6. Alat uji standar Proctor (SNI 03-1742-1989)

7. Alat uji CBR (California Bearing Ratio)

8. Prosedur Analisa saringan (SNI 03-1968-1990)

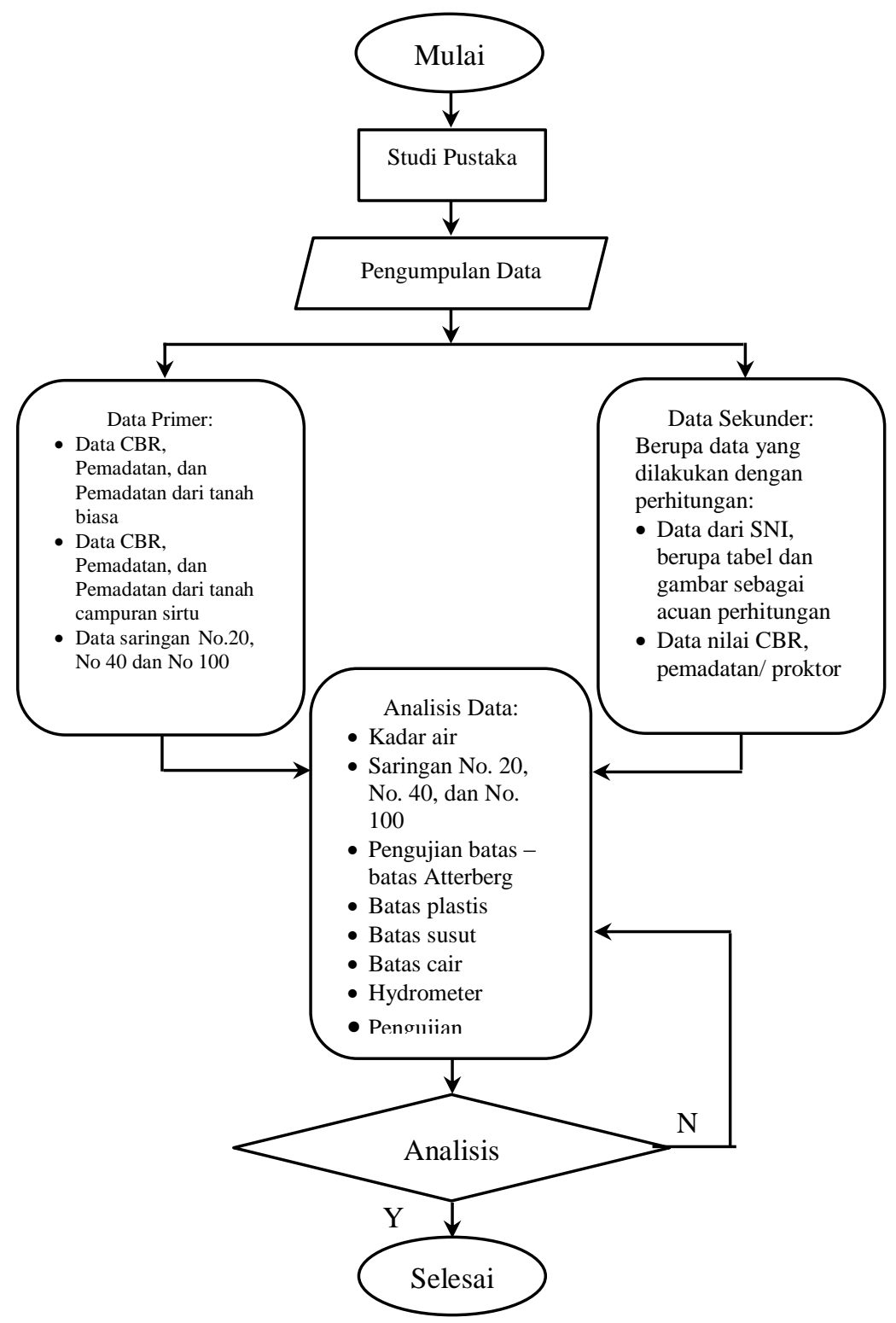

Gambar.1 Diagram alir penelitian 


\section{ANALISIS DAN PEMBAHASAN}

Pada pembahasan ini, akan membahas serta menganalisa sifat-sifat tanah dasar, karakteristik tanah dasar, jenis tanah dasar serta pembagian klasifikasi tanah dasar. Setelah menganalisa tanah dasar tersebut, maka tanah tersebut akan di stabilisasikan dengan sirtu alam dengan variasi pencampuran 15\%, 20\% dan $30 \%$ dari berat kering tanah.

Pengujian pendahuluan dilakukan untuk mendapatkan sifat-sifat, karakteristik, jenis serta klasifikasi dari tanah lempung.Tanah lempung ini diambil dari Koya Timur Distrik Muara Tami Kota Jayapura. Sifat-sifat tanah tersebut yang akan diuji adalah sebagai berikut : pengujian kadar air, pengujian berat isi, pengujian berat jenis, pengujian atterberg (batas cair, batas plastis dan batas susut), pengujian hydrometer, pengujian analisa saringan (gradasi), pengujian pemadatan (proctor) dan CBR (California bearing rasio)

Pengujian Kadar Air Tanah

Memeriksa kadar air dari suatu contoh tanah. Kadar air adalah perbandingan antara (massa/berat) air yang dikandung tanah dan (massa/berat) kering tanah. Pada pengujian ini dibuat 2 sampel contoh tanah untuk pengujian agar dapat diambil rata - rata dari hasil pengujian kadar air.

\begin{tabular}{|c|c|c|c|c|c|}
\hline \multicolumn{6}{|c|}{ KADAR AIR ASLI } \\
\hline \multirow{2}{*}{\multicolumn{4}{|c|}{$\begin{array}{l}\text { NOMOR CONTOH } \\
\text { NOMOR CAWAN }\end{array}$}} & \multicolumn{2}{|c|}{ TANAH } \\
\hline & & & & 1 & II \\
\hline No & & RUMUS & SATUAN & & \\
\hline 1 & $\begin{array}{l}\text { BERAT CAWAN + SAMPEL CONTH TANAH } \\
\text { BASAH }\end{array}$ & & gr & 41,90 & 44,00 \\
\hline 2 & $\begin{array}{l}\text { BERAT CAWAN + SAMPEL CONTOH TANAH } \\
\text { KERING }\end{array}$ & & gr & 37,00 & 38,30 \\
\hline 3 & BERAT CAWAN & & gr & 22,10 & 22,70 \\
\hline 4 & BERAT AIR & "W1 - W2 & $\mathrm{gr}$ & 4,90 & 5,70 \\
\hline 5 & BERAT CONTOH TANAH KERING & "W2 - W3 & $\mathrm{gr}$ & 14,90 & 16,60 \\
\hline 6 & KADAR AIR & "(W4/W5)x100 & $\%$ & 32,89 & 34,34 \\
\hline 7 & RATA - RATA & & $\%$ & & \\
\hline
\end{tabular}

Tabel 1 Pengujian kadar air

Berat Jenis

\begin{tabular}{|c|c|c|c|c|}
\hline \multicolumn{5}{|c|}{ BERAT JENIS (SPECIFIK GRAVITY) } \\
\hline \multirow{2}{*}{\multicolumn{3}{|c|}{$\begin{array}{l}\text { NOMOR CONTOH/KEDALAMAN } \\
\text { MOMOR PICNOMETER }\end{array}$}} & \multicolumn{2}{|c|}{ TANAH } \\
\hline & & & I & II \\
\hline No & NAMA & RUMUS & A & $\mathrm{B}$ \\
\hline 1 & BERAT PICNOMETER + CONTOH & W2 & 64,7 & 60,2 \\
\hline 2 & BERAT PICNOMETER & W1 & 44,7 & 40,2 \\
\hline 3 & BERAT TANAH & $\mathrm{Wt}=\mathrm{w} 2-\mathrm{w} 1$ & 20 & 20 \\
\hline 4 & SUHU & $\mathrm{c}$ & 28 & 28 \\
\hline 5 & BERAT PICNOMETER + AIR + TANAH & w3 & 157,7 & 155 \\
\hline 6 & BERAT PICNOMETER + AIR PADA TC & w4 & 144,9 & 145 \\
\hline 7 & $\mathrm{~W} 5=\mathrm{W} 2-\mathrm{W} 1+\mathrm{W} 4$ & & 164,9 & 165 \\
\hline 8 & $\mathrm{~W} 6=\mathrm{W} 5-\mathrm{W} 3$ & & 7,2 & 9,6 \\
\hline \multirow[t]{2}{*}{9} & BERAT JENIS & WT / ( W5- W3 ) & 2,78 & 2,08 \\
\hline & \multicolumn{2}{|l|}{ RATA - RATA } & \multicolumn{2}{|c|}{2,43} \\
\hline
\end{tabular}

Tabel 2 Pengujian berat jenis $(G s)$ 


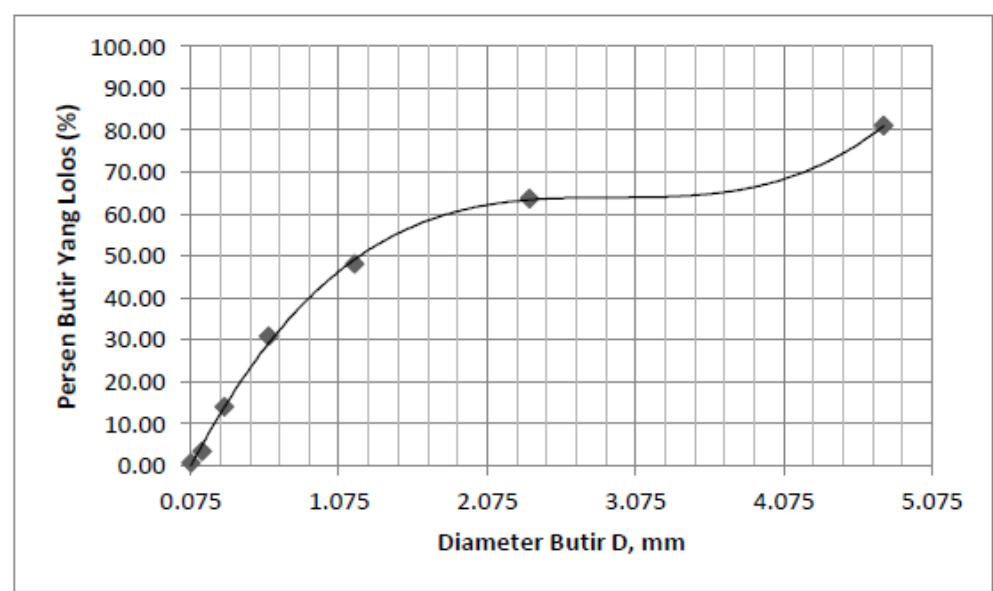

Gambar 2 Grafik distribusi ukuran butir sirtu alam

\begin{tabular}{|l|c|c|c|c|c|}
\hline \multicolumn{5}{|c|}{ PEMERIKSAAN KONSISTENSI ATTERBERG } \\
\cline { 3 - 6 } & \multicolumn{5}{|c|}{ BATAS CAIR } \\
\hline BANYAKNYA PUKULAN & $\mathrm{gr}$ & $\mathrm{I}$ & 26 & 20 & 5 \\
\hline NOMOR CAWAN & $\mathrm{gr}$ & 27,90 & 32,40 & $\mathrm{III}$ & $\mathrm{IV}$ \\
\hline BERAT CAWAN + CONTOH BASAH & $\mathrm{II}$ & 40,40 \\
\hline BERAT CAWAN + CONTOH KERING & $\mathrm{gr}$ & 26,80 & 30,10 & 28,10 & 35,10 \\
\hline BERAT AIR & $\mathrm{gr}$ & 1,10 & 2,30 & 2,10 & 5,30 \\
\hline BERAT CAWAN & $\mathrm{gr}$ & 20,00 & 22,00 & 21,40 & 21,30 \\
\hline BERAT CONTOH KERING & $\mathrm{gr}$ & 6.8 & 8,10 & 6,70 & 13,80 \\
\hline KADAR AIR & $\%$ & 16,18 & 28,40 & 31,34 & 38,41 \\
\hline
\end{tabular}

Tabel 3 Pengujian batas cair

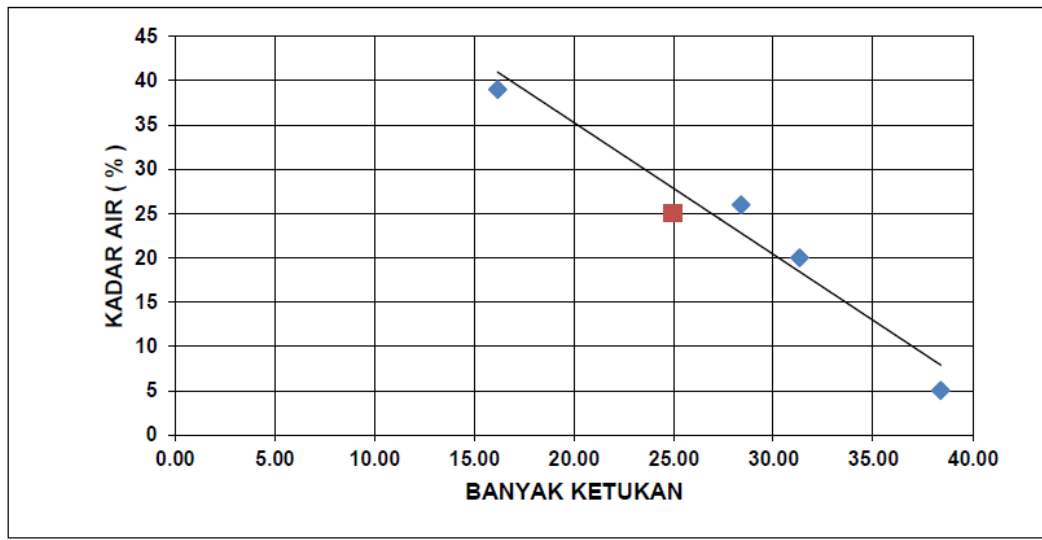

Gambar 3 Grafik analisa batas cair (tanah koya)

\begin{tabular}{|l|c|c|c|}
\hline \multicolumn{3}{|c|}{ PEMERIKSAAN KONSISTENSI ATTERBERG } \\
\hline & \multicolumn{2}{c|}{$\begin{array}{c}\text { BATAS } \\
\text { PLASTIS }\end{array}$} \\
\hline BANYAKNYA PUKULAN & - & - \\
\hline NOMOR CAWAN & $\mathrm{V}$ & $\mathrm{VI}$ \\
\hline BERAT CAWAN + CONTOH BASAH & $\mathrm{gr}$ & 30,70 & 27,80 \\
\hline BERAT CAWAN + CONTOH KERING & $\mathrm{gr}$ & 29,80 & 26,70 \\
\hline BERAT AIR & $\mathrm{gr}$ & 0,90 & 1,10 \\
\hline BERAT CAWAN & $\mathrm{gr}$ & 21,40 & 21,60 \\
\hline BERAT CONTOH KERING & $\mathrm{gr}$ & 8,40 & 5,10 \\
\hline KADAR AIR & $\mathrm{gr}$ & 10,71 & 21,57 \\
\hline \multicolumn{1}{|c|}{ RATA - RATA } & $\%$ & \multicolumn{3}{c|}{16,14} \\
\hline
\end{tabular}

Tabel 4 Pengujian batas plastis 
Indeks Plastisitas

$\mathrm{IP}=\mathrm{LL}-\mathrm{PL}=28,58 \%-16,14 \%$

$=12,40 \%$

\begin{tabular}{|c|c|c|c|c|c|c|c|c|c|c|c|}
\hline \multicolumn{2}{|l|}{ Persiapan contoh uji } & \multicolumn{2}{|c|}{ A } & \multicolumn{2}{|c|}{ B } & \multicolumn{2}{|c|}{ C } & \multicolumn{2}{|c|}{$D$} & \multicolumn{2}{|c|}{$E$} \\
\hline 1 Berat Tanah Basah & $\mathrm{gr}$ & \multicolumn{2}{|c|}{3000} & \multicolumn{2}{|c|}{3000} & \multicolumn{2}{|c|}{3000} & \multicolumn{2}{|c|}{3000} & \multicolumn{2}{|c|}{3000} \\
\hline 2 Kadar air Mula & $\%$ & \multicolumn{2}{|c|}{12,1} & \multicolumn{2}{|c|}{14,1} & \multicolumn{2}{|c|}{16,1} & \multicolumn{2}{|c|}{18,1} & \multicolumn{2}{|c|}{20,1} \\
\hline 3 Kadar Air Akhir & $\%$ & \multicolumn{2}{|c|}{12} & \multicolumn{2}{|c|}{14} & \multicolumn{2}{|c|}{16} & \multicolumn{2}{|c|}{18} & \multicolumn{2}{|c|}{20} \\
\hline 4 Penambahan air & $c c$ & \multicolumn{2}{|c|}{360} & \multicolumn{2}{|c|}{420} & \multicolumn{2}{|c|}{480} & \multicolumn{2}{|c|}{540} & \multicolumn{2}{|c|}{600} \\
\hline \multicolumn{2}{|l|}{ Kepadatan } & \multicolumn{2}{|c|}{ A } & \multicolumn{2}{|c|}{ B } & \multicolumn{2}{|c|}{ C } & \multicolumn{2}{|c|}{$D$} & \multicolumn{2}{|c|}{$E$} \\
\hline 1 Berat Tanah Basah + Cetakan & $\mathrm{gr}$ & \multicolumn{2}{|c|}{5302} & & 386 & 54 & 31 & 541 & & & 358 \\
\hline 2 Berat Cetakan & $\mathrm{gr}$ & 37 & 49 & & 749 & 37 & & 374 & & 37 & 749 \\
\hline 3 Berat Tanah Basah & $\mathrm{gr}$ & 15 & 53 & & 637 & 16 & & 166 & & & 609 \\
\hline 4 |si Cetakan & $\mathrm{cm} 3$ & 93 & 2,7 & & 32,7 & 932 & 2,7 & 932 & & & 32,7 \\
\hline 5 Kepadatan Basah (p) & $\mathrm{gr} / \mathrm{cm} 3$ & 1, & 67 & 1,7 & 76 & 1, & & 1,7 & & 1,7 & 73 \\
\hline 6 Kepadatan Kering (pd) & $\mathrm{gr} / \mathrm{cm} 3$ & 1, & 41 & 1,4 & 46 & 1,4 & & 1,4 & & 1,3 & 39 \\
\hline Kadar air & & $A$ & $A$ & B & B & C & & $D$ & & & $E$ \\
\hline No. Cawan & & 1 & 2 & 3 & 4 & 5 & 6 & 7 & 8 & 9 & 10 \\
\hline 1 Berat Tanah Basah + Cawan & $\mathrm{gr}$ & 56,5 & 56,6 & 57,3 & 58,1 & 57,7 & 57,9 & 58,5 & 59,8 & 59,8 & 60 \\
\hline 2 Berat Tanah Kering + Cawan & $\mathrm{gr}$ & 51,1 & 51,3 & 51,5 & 51,8 & 51,4 & 51,9 & 51,7 & 52,2 & 52,3 & 52,5 \\
\hline 3 Berat air & $\mathrm{gr}$ & 5,4 & 53 & $5,8^{\prime}$ & 6,3 & 6,3 & 6 & 6,8 & 7,6 & 7,5 & 7,5 \\
\hline 4 Berat cawan & $\mathrm{gr}$ & 22 & 21,9 & 21,2 & 21,2 & 22,6 & 22,6 & 21,5 & 21,3 & 21,9 & 21,8 \\
\hline 5 Berat tanah kering & $\mathrm{gr}$ & 29,1 & 29,4 & 30,3 & 30,6 & 28,8 & 29,3 & 30,2 & 30,9 & 30,4 & 30,7 \\
\hline 6 Kadar air & $\%$ & 18,56 & 18,02 & 19,14 & 20,59 & 21,87 & 20,47 & 22,51 & 24.59 & 24,7 & 24,43 \\
\hline 7 Kadar air rata-rata & $\%$ & 18 & & & & 21, & & 23,5 & & &, 55 \\
\hline
\end{tabular}

Tabel 5 Hasil pengujian pemadatan standar tanah (Koya)

Grafik Pemadatan Standar (Proctor)

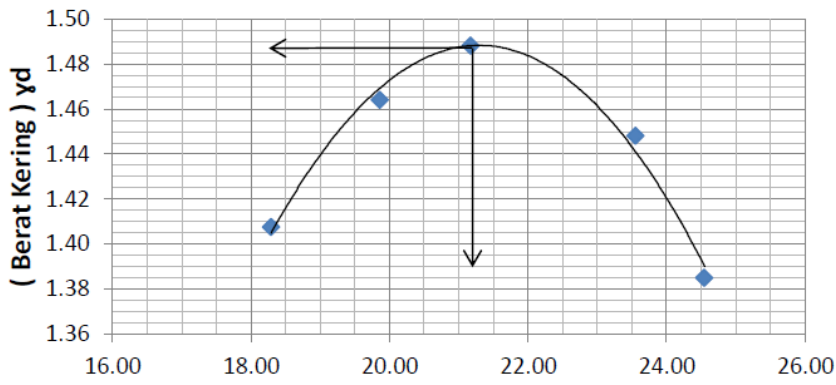

(\%) Kadar Air Optimum

Gambar 4 Hubungan antara kadar air dan kepadatan kering tanah asli

Dari percobaan diatas diperoleh :

Beratisi kering maksimum $=1,49 \mathrm{gr} / \mathrm{cm} 3$

Kadar air optimum $=21.30 \%$ 


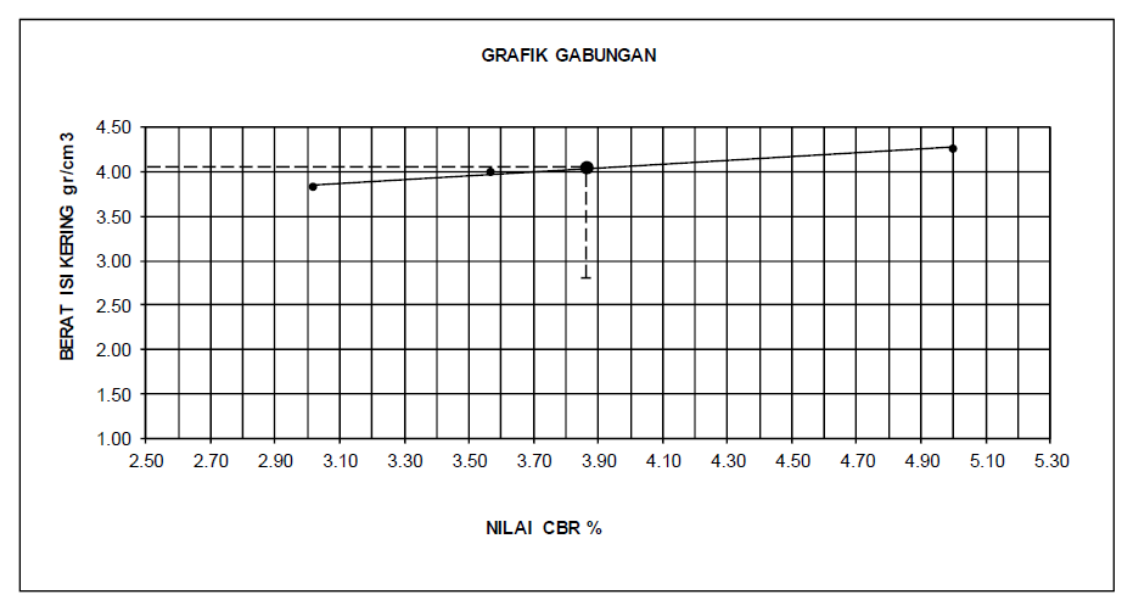

Gambar 5 Grafik CBR Gabungan Tanah Asli

Jadi nilai maksimum CBR tanah dasar tersebut adalah $3.86 \%$,

Pengujian tanah dengan stabilisasi.

Indeks plastisitas adalah selisih antara batas cair dan batas plastis. Penambahan sirtu dengan variasi $15 \%, 20 \%, 30 \%$.

1. Perhitungan indeks plastis dengan tanah $+15 \%$ sirtu

\begin{tabular}{|c|c|c|c|c|c|c|c|}
\hline & & \multicolumn{4}{|c|}{ BATAS CAIR } & \multicolumn{2}{|c|}{$\begin{array}{l}\text { BATAS } \\
\text { PLASTIS }\end{array}$} \\
\hline BANYAK PUKULAN & & 37 & 26 & 15 & 7 & - & - \\
\hline NOMOR CAWAN & & I & II & III & IV & $\mathrm{V}$ & $\mathrm{VI}$ \\
\hline BERAT CAWAN + CONTOH BASAH & gr & 34.8 & 34,3 & 35,3 & 34.4 & 29,4 & 29,4 \\
\hline BERAT CAWAN + CONTOH KERING & $\mathrm{gr}$ & 30,5 & 30 & 30,5 & 29,7 & 27,8 & 27,6 \\
\hline BERAT AIR & $\mathrm{gr}$ & 4,3 & 4,3 & 4,8 & 1,6 & 1,6 & 1,8 \\
\hline BERAT CAWAN & $\mathrm{gr}$ & 20 & 22 & 21,3 & 21,4 & 21,4 & 21,6 \\
\hline BERAT CONTOH KERING & gr & 20,5 & 8 & 8,4 & 6,4 & 6,4 & 6 \\
\hline KADAR AIR & $\%$ & 40,95 & 53,75 & 55,95 & 25 & 25 & 30 \\
\hline \multicolumn{6}{|c|}{ RATA - RATA } & \multicolumn{2}{|c|}{27,5} \\
\hline
\end{tabular}

Tabel 6 Perhitungan IP dengan 15\% sirtu

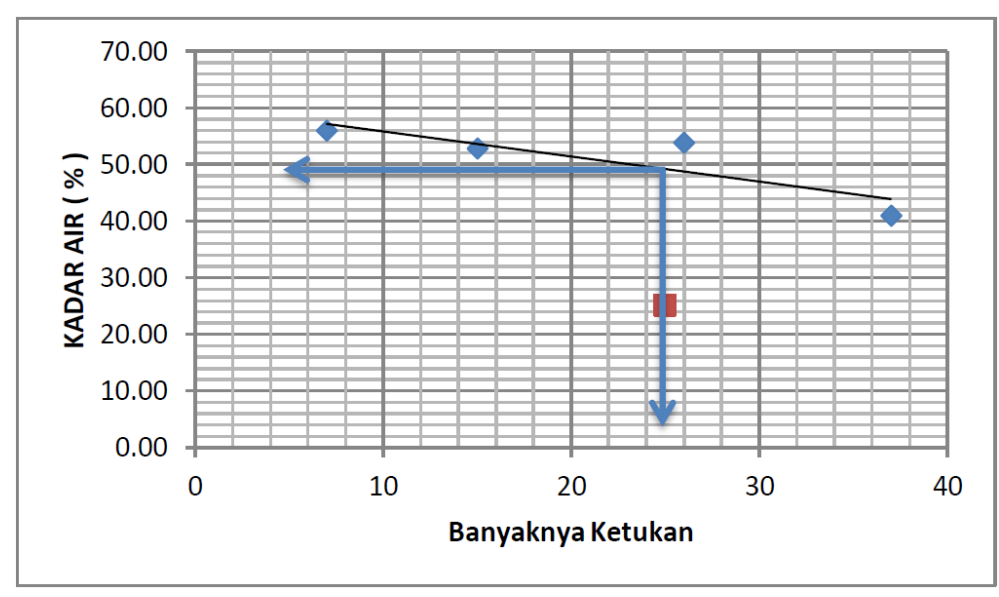

Gambar 6 Grafik Analisa Batas Cair dengan 15\% sirtu

Dari Tabel dapat diketahui batas cair $=50,85 \%$ dan batas plastis $=27,50 \%$, jadi indeks plastisitas dari tanah yang distabilisasi dengan sirtu $15 \%$ adalah 23,35\%.

2. Perhitungan indeks plastis dengan tanah $+20 \%$ sirtu 


\begin{tabular}{l}
\multicolumn{1}{c}{ BATAS } \\
\begin{tabular}{|l|c|c|c|c|c|c|c|}
\hline BANYAK PUKULAN & & 36 & 26 & 18 & 7 & - & - \\
\hline NOMOR CAWAN & & $\mathrm{I}$ & $\mathrm{II}$ & $\mathrm{II}$ & $\mathrm{IV}$ & $\mathrm{V}$ & $\mathrm{VI}$ \\
\hline BERAT CAWAN + CONTOH BASAH & $\mathrm{gr}$ & 35,7 & 37,9 & 37,3 & 38 & 28 & 28,2 \\
\hline BERAT CAWAN + CONTOH KERING & $\mathrm{gr}$ & 31,2 & 32,5 & 31,8 & 32,6 & 26,8 & 26,7 \\
\hline BERAT AIR & $\mathrm{gr}$ & 4,5 & 5,4 & 5,5 & 5,4 & 1,2 & 1,5 \\
\hline BERAT CAWAN & $\mathrm{gr}$ & 20 & 22 & 21,4 & 21,3 & 21,4 & 21,6 \\
\hline BERAT CONTOH KERING & $\mathrm{gr}$ & 11,2 & 10,5 & 10,4 & 11,3 & 5,4 & 5,1 \\
\hline KADAR AIR & $\%$ & 40,18 & 51,43 & 52,88 & 47,79 & 22,22 & 29,41 \\
\hline
\end{tabular}
\end{tabular}

Tabel 7 Perhitungan IP dengan 20\% sirtu

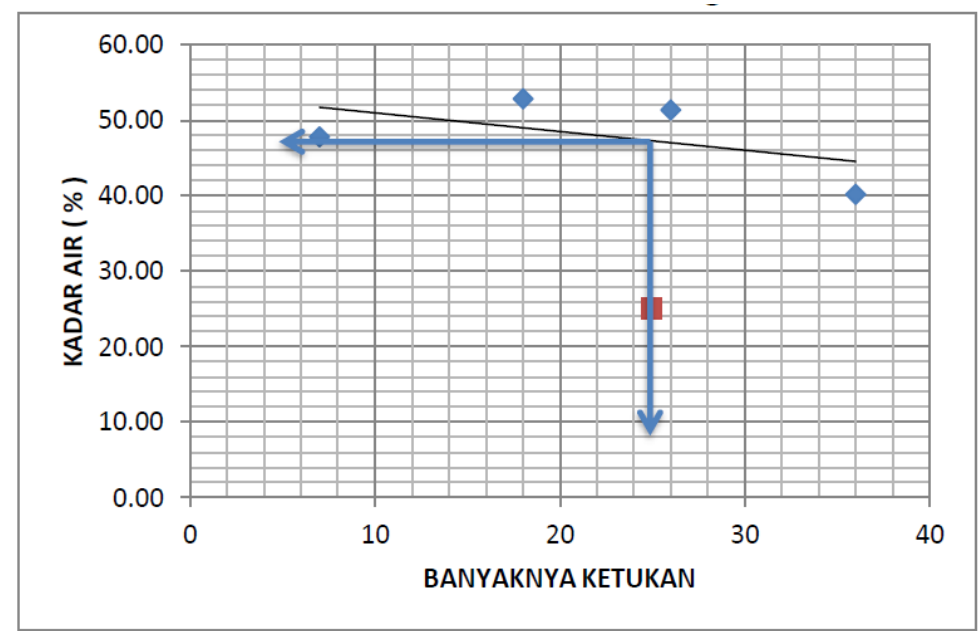

Gambar 7 Grafik Analisa Batas Cair dengan 20\% sirtu

Dari Tabel 7 dan Gambar 7 dapat diketahui batas cair $=48,07 \%$ dan batas plastis $=25,82 \%$, jadi indeks plastisitas dari tanah yang distabilisasi dengan sirtu $20 \%$ adalah $22,25 \%$.

3. Perhitungan indeks plastis dengan tanah $+30 \%$ sirtu

\begin{tabular}{l}
\multicolumn{1}{c}{ BATAS } \\
\begin{tabular}{|l|c|c|c|c|c|c|c|}
\hline BANYAK PUKULAN & \multicolumn{1}{c}{ BATAS CAIR } & \multicolumn{1}{c|}{ PLASTIS } \\
\hline NOMOR CAWAN & & 34 & 25 & 18 & 8 & - & - \\
\hline BERAT CAWAN + CONTOH BASAH & & $\mathrm{I}$ & $\mathrm{II}$ & $\mathrm{III}$ & $\mathrm{IV}$ & $\mathrm{V}$ & $\mathrm{VI}$ \\
\hline BERAT CAWAN +CONTOH KERING & $\mathrm{gr}$ & 38,6 & 38,7 & 37,7 & 40,6 & 28,4 & 28,4 \\
\hline BERAT AIR & $\mathrm{gr}$ & 33,8 & 33,4 & 32,5 & 33,8 & 27 & 26,9 \\
\hline BERAT CAWAN & $\mathrm{gr}$ & 4,8 & 5,3 & 5,2 & 6,8 & 1,4 & 1,5 \\
\hline BERAT CONTOH KERING & $\mathrm{gr}$ & 20 & 22 & 21,4 & 21,3 & 21,4 & 21,6 \\
\hline KADAR AIR & $\mathrm{gr}$ & 13,8 & 11,4 & 11,1 & 12,5 & 5,6 & 5,3 \\
\hline & $\%$ & 34,78 & 46,49 & 46,85 & 54,4 & 25 & 28,3 \\
\hline
\end{tabular}
\end{tabular}

Tabel 8 Perhitungan IP dengan 30\% sirtu 


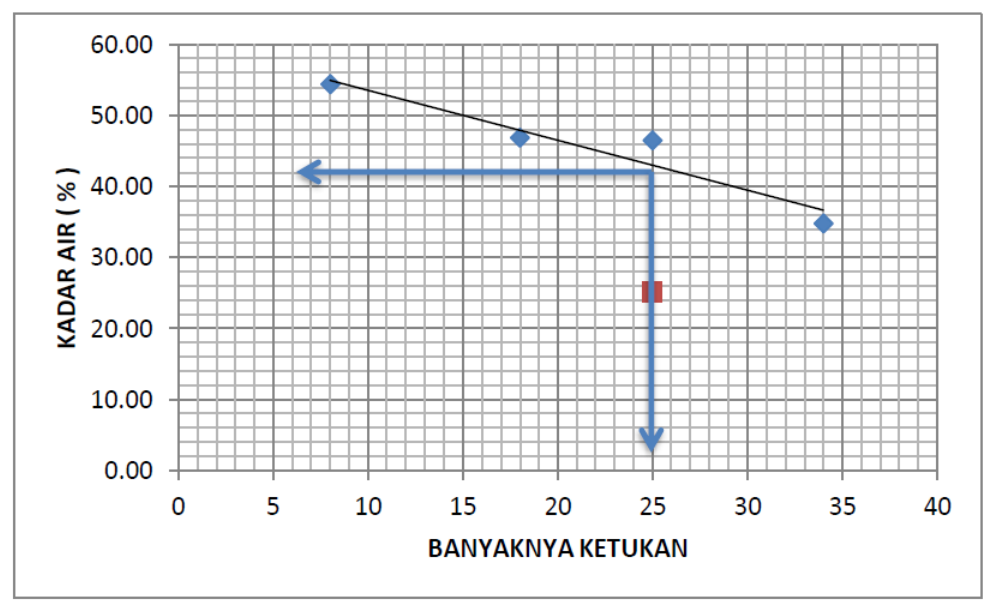

Gambar 8 Grafik Analisa Batas Cair dengan 30\% sirtu

Stabilisasi Sirtu

Pengaruh penambahan sirtu terhadap nilai kepadatan tanah (CRB). Uji pemadatan dilakukan dengan menggunakan metode standar CBR (California Bearing Ratio), pengujian kepadatan dengan variasi kadar Sirtu (15\%, 20\%, dan $30 \%$ ) terhadap tanah memperlihatkan bahwa terjadi peningkatan pada berat volume kering. Hasil pengujian disajikan pada Gambar dan Tabel berikut:

1. Penambahan $15 \%$ sirtu CBR gabungan $15 \%$

\begin{tabular}{|c|r|r|c|}
\hline \multicolumn{4}{|c|}{ CBR } \\
\hline Tumbukan & 0,1 & 0,2 & Rata" \\
\hline 10 & 4,33 & 4,22 & 4,28 \\
\hline 30 & 5,83 & 5,67 & 5,75 \\
\hline 65 & 6,83 & 6,38 & 6,61 \\
\hline \multicolumn{4}{|c|}{ Rata - rata isi CBR $=5,54$} \\
\hline
\end{tabular}

berat isi rata-rata $\mathrm{CBR}$

\begin{tabular}{|r|r|}
\hline 10 & 4,08 \\
\hline 30 & 4,14 \\
\hline 65 & 4,3 \\
\hline
\end{tabular}

Rata - rata berat isi $\mathrm{CBR}=4,17$

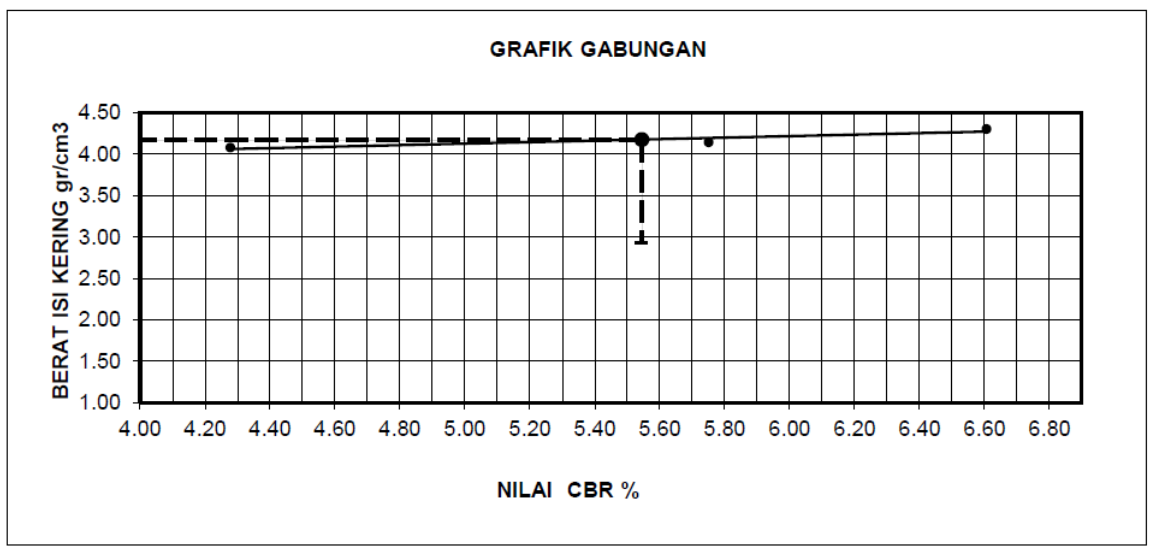


Gambar 9 Grafik CBR gabungan stabilisasi 15\%

Cara pemadatan : Modified

Berat Jenis $\quad: 2,43 \mathrm{gram} / \mathrm{cm}^{3}$

Kadar Air Optimum : $21,30 \%$

yd Maksimum $\quad: 4,17 \mathrm{gram} / \mathrm{cm}^{3}$

95\% $\gamma \mathrm{d}$ Maksimum $: 3,96 \mathrm{gram} / \mathrm{cm}^{3}$

CBR Maximum : $: 5,54 \%$

2. Penambahan $20 \%$ sirtu

CBR stabilisasi $20 \%$

\begin{tabular}{|c|r|r|c|}
\hline \multicolumn{5}{|c|}{ CBR } \\
\hline Tumbukan & 0,1 & 0,2 & Rata" \\
\hline 10 & 6,83 & 6,56 & 6,69 \\
\hline 30 & 7,5 & 7,07 & 7,28 \\
\hline 65 & 8 & 7,56 & 7,78 \\
\hline \multicolumn{4}{|c|}{ Rata - rata isi CBR $=7,25$} \\
\hline
\end{tabular}

\begin{tabular}{|} 
berat isi rata-rata CBR \\
\hline 10 & 3,83 \\
\hline 30 & 4 \\
\hline 65 & 4,27 \\
\hline
\end{tabular}

Rata - rata isi $\mathrm{CBR}=4,03$

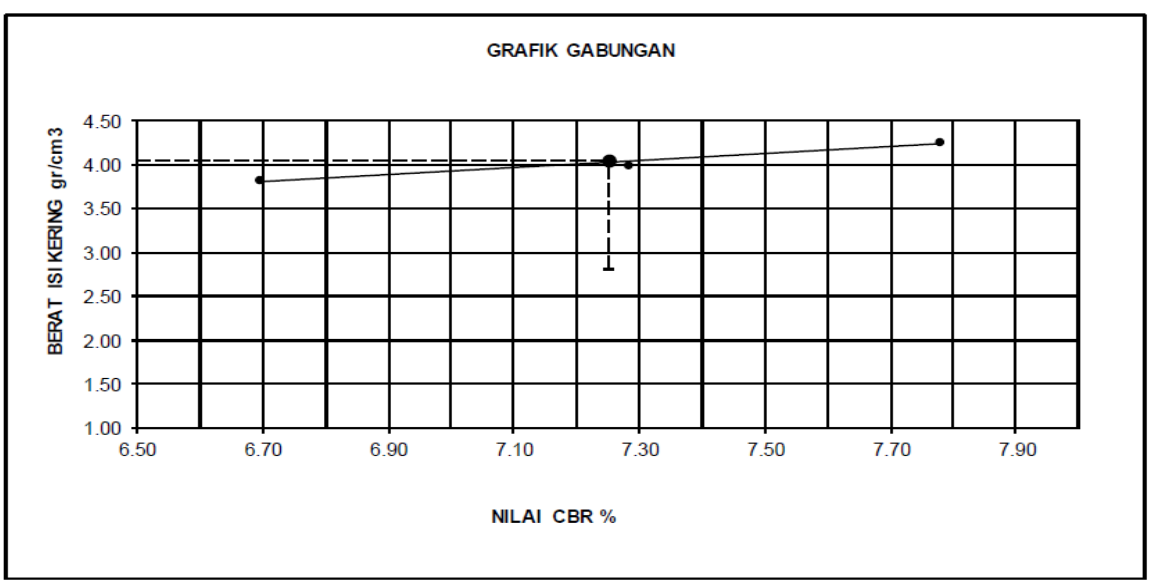

Gambar 10 Grafik CBR gabungan stabilisasi 20\%

Cara pemadatan : Modified

Berat Jenis $\quad: 2,43 \mathrm{gram} / \mathrm{cm}^{3}$

Kadar Air Optimum : $21,30 \%$

yd Maksimum $\quad: 4,03 \mathrm{gram} / \mathrm{cm}^{3}$

95\% $\gamma \mathrm{d}$ Maksimum $: 3,83 \mathrm{gram} / \mathrm{cm}^{3}$

CBR Maximum : : $7,25 \%$ 
3. Penambahan $30 \%$ sirtu CBR stabilisasi 30\%

\begin{tabular}{|c|r|r|c|}
\hline \multicolumn{5}{|c|}{ CBR } \\
\hline Tumbukan & 0,1 & 0,2 & Rata" \\
\hline 10 & 7,33 & 7 & 7,17 \\
\hline 30 & 7,67 & 7,22 & 7,44 \\
\hline 65 & 8,5 & 7,78 & 8,14 \\
\hline \multicolumn{4}{|c|}{ Rata - rata isi CBR $=7,25$} \\
\hline
\end{tabular}

CBR stabilisasi $30 \%$

berat isi rata-rata CBR

\begin{tabular}{|r|r|}
\hline 10 & 3,83 \\
\hline 30 & 4 \\
\hline 65 & 4,27 \\
\hline
\end{tabular}

Rata - rata isi $C B R=4,03$

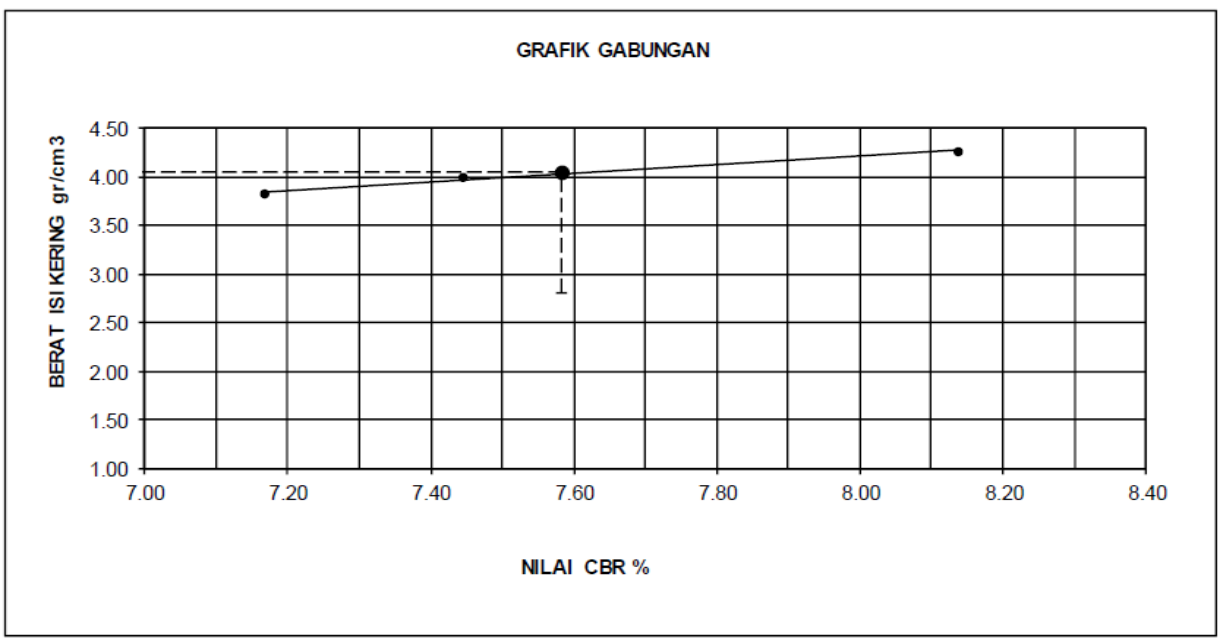

Gambar 11 Grafik CBR gabungan stabilisasi 30\%

Cara pemadatan : Modified

Berat Jenis $\quad: 2,43 \mathrm{gram} / \mathrm{cm}^{3}$

Kadar Air Optimum : $21,30 \%$

yd Maksimum

: $4,03 \mathrm{gram} / \mathrm{cm}^{3}$

95\% $\gamma$ d Maksimum $: 3,83 \mathrm{gram} / \mathrm{cm}^{3}$

CBR Maximum $\quad: 7,58 \%$ 


\section{KESIMPULAN}

Dari hasil pengujian yang dilakukan dapat ditarik beberapa kesimpulan sebagai berikut:

1. Nilai CBR laboratorium subgrade lokasi penelitian sebesar 3,86\%. Maka perlu ditingkatkan lagi, dengan cara melakukan stabilisasi.

2. Berdasarkan nilai CBR tanah yang distabilisasi dengan sirtu telah mendapatkan nilai yang baik diantaranya adalah sebagai berikut:

a. CBR stabilisasi $15 \%=5.54 \%$

b. CBR stabilisasi $20 \%=7.25 \%$

c. CBR stabilisasi $30 \%=7.58 \%$

3. Jadi stabilisasi tanah dasar (khususnya lempung) menggunakan sirtu, dapat menaikan nilai tanah dasar (subgrade) tersebut dengan variasi campuran $15 \%-30 \%$

4. Dari hasil pengujian yang dilakukan dapat disimpulkan bahwa dengan penambahan stabilisasi sirtu minimum $20 \%$ telah dapat memenuhi standar CBR minimum yaitu di atas $6 \%$.

\section{DAFTAR PUSTAKA}

Al-Rawas, A. A, dan Goosen, F. A, 2006, Expansive Soil (Recent Advances in Characterization and Treatment),

Hary Chritady Hardiyatmo, Stabilisasi Tanah untuk Perkerasan Jalan, Universitas Gadjah Mada.

Karl Terzaghi Ralph B.Peck. (1987), Mekanika Tanah Dalam Praktek Rekayasa, Edisi Kedua, Penerbit Erlangga, Jakarta. 